\section{Fibrinolytic therapy with tPA failed because it was based on a flawed concept}

\author{
Victor Gurewich*
}

Professor of Medicine, Harvard Medical School, Vascular Research Laboratory, 763D Concord Ave, Cambridge, MA 02138, USA

\section{Abstract}

Fibrinolytic therapy has become synonymous with tissue plasminogen activator (tPA) based on the belief that tPA alone was responsible for natural fibrinolysis. Although this assumption was belied from the outset by disappointing clinical results, it persisted, eventually causing fibrinolysis to be discredited and replaced by an endovascular procedure. Since time to reperfusion is the critical determinant of outcome, which in acute myocardial infarction (AMI) means within two hours, a time-consuming hospital procedure is ill-suited as first line treatment. For this purpose, fibrinolysis is more fitting. The assumption that IPA is responsible for fibrinolysis is contradicted by published findings. Instead, tPA 's function is limited to the initiation of fibrinolysis, which is continued by urokinase plasminogen activator (UPA) and that has the dominant effect. TPA and UPA gene deletion and clot lysis studies showed the activators have complementary functions, requiring both for a full effect at fibrin-specific doses. They are also synergistic in combination thereby requiring lower doses for efficacy. A clinical proof of concept study in $101 \mathrm{AMI}$ patients who were treated with a $5 \mathrm{mg}$ bolus of tPA followed by a 90 minute infusion of prouPA, the native form of UPA. A near doubling of the $24 \mathrm{~h}$ TIMI-3 infarct artery patency rate was obtained compared to that in the best of the tPA trials (GUSTO). In further contrast to tPA, there were no reocclusions and the mortality was only $1 \%$ [1]. A sequential combination of both activators, mimicking natural fibrinolysis, holds promise to significantly improve the efficacy and safety of therapeutic fibrinolysis.

\section{More Information}

*Address for Correspondence: Victor Gurewich, MD, Professor of Medicine, Harvard Medical School, Vascular Research Laboratory, 763D Concord Ave, Cambridge, MA 02138, USA, Tel: 617-661-0567; Email: vgurewich@tsillc.net

Submitted: 17 April 2020

Approved: 15 June 2020

Published: 16 June 2020

How to cite this article: Gurewich V. Fibrinolytic therapy with IPA failed because it was based on a flawed concept. J Cardiol Cardiovasc Med. 2020; 5: 131-135.

DOI: 10.29328/journal.jccm.1001099

Copyright: () 2020 Gurewich V. This is an open access article distributed under the Creative Commons Attribution License, which permits unrestricted use, distribution, and reproduction in any medium, provided the original work is properly cited.

Keywords: Endogenous fibrinolysis; tPA; uPA; Fibrinolytic therapy

(D) Check for updates

OPEN ACCESS

\section{Introduction}

The science historian Thomas Kuhn observed that science tends not to progress as a linear accumulation of new knowledge, but rather undergoes periodic revolutions which he called paradigm shifts [2]. He found that a paradigm shift was required before new findings that challenge a longaccepted concept or established practice are adopted by the scientific community. This observation is particularly relevant to fibrinolysis where a therapeutic regimen based on the premise that tPA was responsible for fibrinolysis resulted in fibrinolysis becoming prematurely discredited and replaced by primary percutaneous coronary intervention (PCI).

PCI is now the treatment of choice for AMI, and endovascular procedures are being used increasingly in ischemic stroke as well. However, a technically demanding hospital procedure inevitably delays myocardial or brain reperfusion on which the salvage of function and reduction of mortality depend.

In non-human primates, the duration of coronary occlusion is the main determinant of myocardial infarct size [3]. In human AMI, when coronary reperfusion takes place within two hours of the event, infarct size measured $2 \%$ by scan whereas the figure jumped to $12 \%$ one-hour later. After four hours, little further cardiac damage occurred showing that it was already at maximum [4]. Similarly, in a study of primary PCI, pre-procedural patency (TIMI-3) and not post PCI patency was the independent predictor of one year survival [5]. In another study, the 6 month mortality in higher risk AMI patients increased from $5 \%$ to $13 \%$ when reperfusion was delayed from less than two to four or more hours [6]. These findings underscore the importance of prompt reperfusion, preferably within two hours of the event.

For most patients, this is achievable only with fibrinolytic therapy. Unfortunately, current fibrinolytic therapy with tPA is neither sufficiently effective nor safe enough to make this a realistic option. Even when TPA was used as an adjunctive treatment, so-called facilitated PCI, tPA had to be abandoned because it increased the bleeding and rethrombosis rate[7]. 
Therefore, a better, safer fibrinolytic regimen is required to make early reperfusion in AMI or ischemic stroke feasible.

\section{Background}

tPA is a natural activator and the only one isolated from normal human plasma [8], and was assumed to be responsible for endogenous fibrinolysis. Its properties of high fibrin-affinity and fibrin-dependent plasminogen activation contrasted with the non-specific activators, streptokinase (SK) and two-chain (tc) uPA, available at the time. Therefore, tPA was confidently expected to be both more effective and safer.

Surprisingly, three mega-trials comparing tPA with SK in a total of 95,740 AMI patients [9-11] showed that the death rate with tPA was not significantly lower than that with SK [12]. Moreover, tPA caused significantly more intracranial hemorrhage than SK $[10,11]$. These results were paradoxical in light of the differences in their fibrinolytic properties, and yet no explanation for the findings was ever offered.

Had this occurred, it might have raised questions about whether the assumption that tPA was solely responsible for endogenous fibrinolysis was still tenable.

Nonetheless, after these trials tPA was given regulatory approval for AMI in 1981, and it remains the fibrinolytic of choice. However, due to tPA's continued disappointing efficacy and intracranial bleeding complications, it has been replaced by PCI as the treatment of choice in AMI, and endovascular procedures are being used increasingly in ischemic stroke as well.

Although PCI solved the problem of tPA bleeding complications, a hospital-based procedure inevitably delays reperfusion beyond the optimal two-hour reperfusion window for most patients. For first-line therapy, more rapid reperfusion is needed.

\section{The endogenous fibrinolytic system}

The standard tPA dose in AMI is $100 \mathrm{mg}$ infused over 90 minutes, giving a plasma concentration of about $3-4 \mu \mathrm{g} / \mathrm{mL}$ [11]. By comparison, the endogenous tPA plasma concentration is $10-12 \mathrm{ng} / \mathrm{mL}$, about 1,000-fold less, of which at least half is in an inactive complex with plasminogen activator inhibitor-1 (PAI-1) [13]. Despite this, the natural endogenous system is continuously lysing fibrin.

This is evidenced by the invariable presence of the fibrin degradation product Ddimer, the normal plasma concentration of which is $112-250 \mathrm{ng} / \mathrm{mL}$. Since D-dimer is $\sim 60 \%$ of the fibrin monomer mass, this represents a steady state of $\sim 1 \mathrm{mg}$ of lysed fibrin in a plasma volume of 3,000 mL. Only in a patient with a potent autoantibody to thrombin was the D-dimer plasma concentration reported to be closer to zero (12-32 $\mathrm{ng} / \mathrm{mL}$ ) [14]. In the presence of venous thromboembolism, the D-dimer concentration increases by as much as 30 -fold, representing lysis of a corresponding amount of fibrin by the endogenous system.

Evidently, fibrin formation is ongoing even in normal individuals and is kept in control by endogenous fibrinolysis, a defense system that also has a significant reserve capacity as shown by its response to thromboembolism. The small amount of endogenous free tPA available cannot alone account for this efficacy, implicating an additional activator.

\section{Physiological fibrinolysis requires two plasminogen activators}

There are two plasminogen activators in blood, the second one being UPA. In contrast to tPA, most of the UPA is carried on the surface of platelets $[15,16]$ and monocytes [17] rather than being free in the plasma, explaining why it has often eluded detection.

The native form of uPA is a single-chain proenzyme, prouPA, which is activated by plasmin to the enzyme, tcuPA. Neither form of uPA has fibrin affinity, in contrast to tPA, but instead there is a UPA cell surface receptor (UPAR) [18]. This allows uPA to induce pericellular plasminogen activation important for cell migration. This important uPA function led to the erroneous conclusion that uPA's activity was limited to the extravascular space [19]. The belief that uPA was not involved in intravascular fibrinolysis persisted [20] and perpetuated the misunderstanding responsible for the unquestioned use of tPA alone for fibrinolytic therapy.

No paradigm shift has yet taken place, which may explain why published evidence that uPA has an important and even dominant function in fibrinolysis has been ignored. For example, tPA and uPA gene knockout studies in mice showed that deleting tPA alone did not diminish endogenous clot lysis much, whereas uPA deletion caused significant inhibition of lysis. When both TPA and uPA genes were deleted, fibrinolysis was essentially arrested [21], suggesting that tPA and UPA were synergistic in combination. Similarly, uPA but not tPA deletion caused spontaneous fibrin deposition in mice, while deleting both activators induced substantial intravascular fibrin deposition [22].

The more potent effect of uPA over tPA can be attributed at least in part to UPA having two fibrinolytic forms, the singlechain proenzyme and the two-chain enzyme, whereas the single and two-chain forms of tPA have identical fibrinolytic activities [23]. The fibrinolytic activity of tPA also has only a single known fibrin binding site that is on lysine $\gamma$-(312325 ) of the D-domain of intact fibrin [24] where it induces activation of a proximally bound plasminogen.

The properties of tPA and prouPA and their fibrinolytic functions are complementary [25], and in combination they are synergistic both in vivo [26] and in clot lysis studies in vitro [27]. Both activators are, therefore, required for a full 
fibrinolytic effect at fibrin-specific doses. Fibrinolysis with tPA alone was inevitably going to be inadequate, explaining its history. Unfortunately, since tPA has been equated with fibrinolysis in general, the latter has also become discredited.

\section{The sequential combination of tPA and prouPA responsible for fibrinolysis}

In the biological system, when an intravascular thrombus forms threatening blood flow, it triggers the release of tPA from the vessel wall where it is stored. The tPA then binds to the thrombus at its binding site [24] proximal to plasminogen on lysine A 157 of the fibrin D-domain [28]. This tPA-fibrinplasminogen ternary complex promotes tPA's activity about 1,000-fold [29] and initiates fibrin degradation. The remaining unbound tPA is rapidly cleared from plasma $\left(\mathrm{T}_{1 / 2} \sim 5 \mathrm{~min}\right)$ and inhibited by plasminogen activator inhibitor-1 (PAI-1). This limits tPA's lytic effect, which is essential for the protection of hemostatic fibrin. Hemostatic fibrin has the same ternary complex tPA and plasminogen binding sites that are on the D-domain of intact fibrin, making it vulnerable to lysis by tPA. Lysis of hemostatic fibrin was found to be the principal cause of bleeding complications during tPA fibrinolytic therapy [30].

The initiation of fibrin degradation by tPA creates new plasminogen binding sites on fibrin [31] that are two in number [32]. The first of these is a triple carboxyterminal lysine binding site on the E-domain of partially degraded fibrin that induces a unique conformational change in plasminogen. Against this conformation, the intrinsic activity of prouPA is promoted about 250 -fold enabling it to activate this plasminogen [33], a reaction that is accompanied by reciprocal activation of prouPA by plasmin [34]. The resultant tcuPA then activates the remaining fibrin-bound plasminogen and completes fibrinolysis. Therefore, tPA activates the first fibrin-bound plasminogen and UPA the remaining two, consistent with its dominant fibrinolytic effect $[21,22]$.

The tPA initiation of plasminogen activation on the fibrin D-domain and that by prouPA on the E-domain was confirmed by studies with these isolated fibrin domains. Plasminogen activation by tPA was promoted only by fibrin fragment-D while that by prouPA was promoted only by partially degraded fibrin fragment-E [35], consistent with their highly selective and complementary modes of action [25]. As a result, effective lysis at safe, fibrin-specific doses can be achieved only with both activators in combination.

When only tPA is used, as in standard fibrinolytic therapy, a high non-specific dose is required for tPA to non-specifically activate the two uPA-specific fibrin-bound plasminogens. At this dose, hemorrhagic complications due to lysis of hemostatic fibrin become a significant risk [30]. Furthermore, since the promoting effect by the synergistic combination is absent, fibrinolysis is also less effective with tPA alone [26,27].

\section{A clinical proof of concept}

A multicenter clinical trial using the biological regimen of a sequential activator combination was conducted in 101 patients with AMI. A mini-bolus of tPA was administered iv to initiate fibrin degradation, followed by a modest infusion of prouPA. The first 10 patients received a $10 \mathrm{mg}$ bolus but this was found to be excessive, so the remaining 91 patients received $5 \mathrm{mg}$ of tPA ( $5 \%$ of the standard therapeutic dose) followed by a prouPA infusion of $40 \mathrm{mg} / \mathrm{h}$ for 90 minutes in all patients. Complete patency (TIMI-3) of the infarct artery at 24 $\mathrm{h}$ was seen in $82 \%$ of the 28 patients that were re-catheterized. No reocclusions or reinfarctions occurred, consistent with the absence of a prothrombotic effect by prouPA, in contrast to that by tPA [36]. The overall study mortality was only $1 \%$, reflecting the high patency rate without reocclusions [1]. These results compared favorably with those of the best of the tPA trials in which the TIMI-3 patency at $24 \mathrm{~h}$ was only $45 \%$ and the mortality was $6.3 \%$ [37].

These findings represent a proof of concept of the sequential, complementary, synergistic fibrinolytic mechanisms of action of tPA and uPA and of their clinical potential when used in combination. Although the trial was published in a prominent journal, it gained little traction, reflecting Kuhn's observation that a paradigm shift is required before a change in a longestablished concept and practice is accepted [2]. Not long after this trial, the development of prouPA by pharma was unfortunately discontinued.

\section{Conclusion}

Fibrinolysis and fibrinolytic therapy continue to be synonymous with IPA alone, and published evidence to the contrary remains unrecognized. As shown by the PATENT study [1], using both tPA (bolus) followed by prouPA a 6-fold reduction in mortality and almost a doubling of the infarct artery patency was achieved. This underscores the relevance and significance of this discovery and this paper's content. The clinical consequences of this have been significant and costly. A Kuhn paradigm shift is needed and is long overdue.

\section{References}

1. Zarich SW, Kowalchuk GJ, Weaver WD, Loscalzo J, Sassower M, et al. for the PATENT Study Group. Sequential combination thrombolytic therapy for acute myocardial infarction: results of the pro-urokinase and t-PA enhancement of thrombolysis (PATENT) trial. J Am Coll Cardiol. 1995; 26: 374-379.

Pubmed: https://www.ncbi.nlm.nih.gov/pubmed/7608437

2. Kuhn TS. Revolutionary view of the history of science: The structure of scientific revolutions. The Physics Teacher. 1967; 172.

3. Flameng W, Lesaffre E, Vanhaecke J. Determinants of infarct size in nonhuman primates. Bas Res Cardiol. 1990; 85: 392-403.

Pubmed: https://www.ncbi.nlm.nih.gov/pubmed/2241769

4. Brodie BR, Webb J, Cox DA for the EMERALD Investigators. Impact of time to treatment on myocardial reperfusion and infarct size with 
primary percutaneous coronary intervention for acute myocardial infarction. Am J Cardiol. 2007; 99: 16801686.

Pubmed: https://www.ncbi.nlm.nih.gov/pubmed/17560875

5. Deluca G, Ernst N, Zijlstra F, van 't Hof AW, Hoorntje JC, et al Preprocedural TIMI flow and mortality in patients with acute myocardia infarction treated by primary angioplasty. J Am Coll Cardiol. 2004; 43: 1363-1367.

Pubmed: https://www.ncbi.nlm.nih.gov/pubmed/15093868

6. Antoniucci D, Valenti R, Migliorini A, Moschi G, Trapani M, et al Relation of time to treatment and mortality in patients with acute myocardial infarction undergoing primary coronary angioplasty. Am J Cardiol. 2002; 89: 1248-1252.

Pubmed: https://www.ncbi.nlm.nih.gov/pubmed/12031722

7. Stone GW, Gersh BJ. Facilitated angioplasty: paradise lost. Lancet. 2006; 367: 543-546.

Pubmed: https://www.ncbi.nlm.nih.gov/pubmed/16488779

8. Husain SS, Lipinski B, Gurewich V. Rapid purification of high affinity plasminogen activator from human plasma by specific adsorption on fibrin-celite. Proc Nat Acad Sci (USA). 1981; 78: 4265-4269.

Pubmed: https://www.ncbi.nlm.nih.gov/pubmed/6270665

9. Gruppo Italiano Per Lo Studio Della Sopravvivenza Nell'Infarto Miocardico. GISSI-2: A factorial randomised trial of alteplase versus streptokinase and heparin versus no heparin among 12,490 patients with acute myocardial infarction. Lancet. 1990; 336: 65-75.

Pubmed: https://www.ncbi.nlm.nih.gov/pubmed/1975321

10. ISIS-3 Third International Study of Infarct Survival Collaborative Group. ISIS3: a randomized comparison of streptokinase vs tissue plasminogen activator vs anistreplase and of aspirin plus heparin vs aspirin alone among 41,299 cases of suspected acute myocardial infarction. Lancet. 1992; 339: 65-71.

Pubmed: https://pubmed.ncbi.nlm.nih.gov/1347801/

11. The GUSTO Investigators. An international randomized trial comparing four thrombolytic strategies for acute myocardial infarction. $\mathrm{N}$ Eng J Med. 1993; 329: 673-682.

Pubmed: https://pubmed.ncbi.nlm.nih.gov/8204123

12. Brophy JM, Joseph L. Placing trials in context using Bayesian analysis GUSTO revisited by Reverend Bayes. JAMA. 1995; 273: 871-875. Pubmed: https://pubmed.ncbi.nlm.nih.gov/7869558/

13. Chandler WL, Jascur ML, Henderson PJ. Measurement of different forms of tissue plasminogen activator in plasma. Clin Chem. 2000; 46: 38-46.

Pubmed: https://www.ncbi.nlm.nih.gov/pubmed/10620570

14. Baglin TP, Landown R, Frasson R, Huntington JA. Discovery and characterization of an antibody directed against exosite 1 of thrombin. J Thromb Haemos. 2016; 14: 137142.

Pubmed: https://pubmed.ncbi.nIm.nih.gov/26469093

15. Vaughan DE, Vautloutle E, Collen D. Urokinase binds to platelets through a specific saturable, low affinity mechanism. Fibrinolysis. 1990; 4: 141 .

16. Gurewich V, Johnstone M, Loza JP, Pannell R. Pro-urokinase and prekallikrein are both associated with platelets: implications for the intrinsic pathway of fibrinolysis and for therapeutic thrombolysis. FEBS Lett. 1993; 318: 317-321.

Pubmed: https://www.ncbi.nlm.nih.gov/pubmed/8440390

17. Grau E, Moroz LA. Fibrinolytic activity of normal human blood monocytes. Thromb Res. 1989; 53: 145-162.

Pubmed: https://www.ncbi.nlm.nih.gov/pubmed/2922705

18. Vassalli JD, Baccino D, Belin D: A cellular binding site for the $\mathrm{Mr}$ 55,000 form of the human plasminogen activator, urokinase. J Cell
Biol. 1985; 100: 86-92.

Pubmed: https://www.ncbi.nlm.nih.gov/pubmed/3880760

19. Collen D. The plasminogen (fibrinolytic) system. Thromb Haemost. 1999; 82: 259-270.

Pubmed: https://www.ncbi.nlm.nih.gov/pubmed/10605712

20. Longstaff $\mathrm{C}$, Kolev K. Basic mechanisms and regulation of fibrinolysis. J Thromb Haemost. 2015; 13: S98-S105.

Pubmed: https://pubmed.ncbi.nlm.nih.gov/26149056

21. Singh I, Burnand KG, Collins M, Luttun A, Collen D, et al. Failure of thrombus to resolve in urokinase-type plasminogen activator gene-knockout mice: rescue by normal bone marrow-derived cells. Circulation. 2003; 107: 869-875.

Pubmed: https://www.ncbi.nlm.nih.gov/pubmed/12591758

22. Bugge TH, Flick MJ, Danton MJS, Daugherty CC, Romer J, et al. Urokinase-type plasminogen activator is effective in fibrin clearance in the absence of its receptor or tissue-type plasminogen activator. Proc Natl Acad Sci USA. 1996; 93: 5899-5904.

Pubmed: https://www.ncbi.nlm.nih.gov/pubmed/8650190

23. Rijken DC, Hoylaerts M, Collen D. Fibrinolytic properties of one-chain and two-chain human extrinsic (tissue-type) plasminogen activator. J Biol Chem. 1982; 257: 2920-2925.

Pubmed: https://www.ncbi.nlm.nih.gov/pubmed/7199525

24. Medved L, Nieuwenhuizen W. Molecular mechanisms of initiation of fibrinolysis by fibrin. Thromb Haemost. 2003; 89: 409-419. Pubmed: https://www.ncbi.nlm.nih.gov/pubmed/12624622

25. Pannell R, Black J, Gurewich V. The complementary modes of action of tissue plasminogen activator (t-PA) and pro-urokinase (pro-UK) by which their synergistic effect on clot lysis may be explained. J Clin Invest. 1988; 81: 853-859.

Pubmed: https://www.ncbi.nlm.nih.gov/pubmed/2963831

26. Collen D, Stassen JM, Stump DC, Verstraete M. Synergism of thrombolytic agents in vivo. Circulation. 1986; 74: 838-842. Pubmed: https://www.ncbi.nlm.nih.gov/pubmed/3093116

27. Gurewich V, Pannell R. Synergism of tissue-type plasminogen activator (tPA) and single-chain urokinase-type plasminogen activator (scu-PA) on clot lysis in vitro and a mechanism for this effect. Thromb Haemost. 1987; 57: 372-78.

Pubmed: https://www.ncbi.nlm.nih.gov/pubmed/3116707

28. Voskuilen $M$, Vermond $A$, Veeneman $\mathrm{GH}$, et al. Fibrinogen lysine residue Aa157 plays a crucial role in the fibrin-induced acceleration of plasminogen activation, catalyzed by tissue-type plasminogen activator. J Biol Chem. 1987; 262: 5944-5946.

Pubmed: https://www.ncbi.nlm.nih.gov/pubmed/3106345

29. Hoylaerts M, Rijken DC, Lijnen HR, Collen D. Kinetics of the activation of plasminogen by human tissue plasminogen activator. Role of fibrin. J Biol Chem. 1982; 257: 2912-2919.

Pubmed: https://www.ncbi.nlm.nih.gov/pubmed/7199524

30. Marder VJ, Sherry S. Thrombolytic therapy: current status. N Engl J Med. 1988; 318: 1512-1520.

Pubmed: https://www.ncbi.nlm.nih.gov/pubmed/3285216

31. Harpel PC, Chang TS, Verderber E. Tissue plasminogen activator and urokinase mediate the binding of Glu-plasminogen to plasma fibrin I. Evidence for new binding sites in plasmin-degraded fibrin I. J Biol Chem. 1985; 260: 4432-4440.

Pubmed: https://www.ncbi.nlm.nih.gov/pubmed/3156857

32. Suenson E, Lützen O, Thorsen S. Initial plasmin-degradation of fibrin as the basis of a positive feed-back mechanism in fibrinolysis. Eur $\mathrm{J}$ Biochem. 1984; 140: 513-522.

Pubmed: https://pubmed.ncbi.nlm.nih.gov/6233145 
33. Liu J, Gurewich V. Fragment E-2 from fibrin substantially enhances prourokinase-induced glu-plasminogen activation. A kinetic study using a plasminresistant mutant pro-urokinase (Ala-158-rpro-UK). Biochemistry. 1992; 31: 6311-6317.

Pubmed: https://www.ncbi.nlm.nih.gov/pubmed/1385727

34. Petersen LC. Kinetics of reciprocal pro-urokinase/plasminogen activation. Stimulation by a template formed by the urokinase receptor bound to poly (Dlysine). Eur J Biochem. 1997; 245: 316-323.

Pubmed: https://www.ncbi.nlm.nih.gov/pubmed/9151959

35. Liu J, Gurewich V. A comparative study of the promotion of tissue plasminogen activator and pro-urokinase-induced plasminogen activation by fragments $\mathrm{D}$ and $\mathrm{E}-2$ of fibrin. $\mathrm{J}$ Clin Invest. 1991; 88:
2012-2017.

Pubmed: https://www.ncbi.nlm.nih.gov/pmc/articles/PMC295789/

36. Weaver WD, Hartmann JR, Anderson JL, Reddy PS, Sobolski JC, et al New recombinant glycosylated prourokinase for treatment of patients with acute myocardial infarction. J Am Coll Cardio. 1994; 241: 1242-1248. Pubmed: https://pubmed.ncbi.nlm.nih.gov/7930246/

37. GUSTO Angiographic Investigators. The effects of tissue plasminogen activator, streptokinase, or both on coronary-artery patency, ventricular function, and survival after acute myocardial infarction. N Engl J Med. 1993; 329: 1615-1622.

Pubmed: https://pubmed.ncbi.nlm.nih.gov/8232430/ 